Chapter 1

\title{
Maintenance Management Based on Signal Processing
}

\author{
Fausto Pedro García Márquez, \\ Raúl Ruiz de la Hermosa González-Carrato, \\ Jesús María Pinar Perez and Noor Zaman \\ Additional information is available at the end of the chapter \\ http://dx.doi.org/10.5772/52199
}

\section{Wind Turbines}

Most of the wind turbines are three-blade units (Figure 1.) [55]. Once the wind drives the blades, the energy is transmitted via the main shaft through the gearbox (supported by the bearings) to the generator. The generator speed must be as near as possible to the optimal for the generation of electricity. At the top of the tower, assembled on a base or foundation, the housing or nacelle is mounted and the alignment with the direction of the wind is controlled by a yaw system. There is also a pitch system in each blade. This mechanism controls the wind power and sometimes is employed as an aerodynamic brake. The wind turbine features a hydraulic brake to stop itself when it is needed. Finally, there is a meteorological unit that provides information about the wind (speed and direction) to the control system.

\subsection{Maintenance in Wind Turbines}

Maintenance is a key tool to ensure the operation of all components of a set. One of the objectives is to use available resources efficiently. The classical theory of maintenance was focused on the corrective and preventive maintenance [9] but alternatives to corrective and preventive maintenance have appeared in recent years. One of them is Condition Based Maintenance, which ensures the continuous monitoring and inspection of the wind turbine detecting emerging faults and organizing maintenance tasks that anticipate the failure [59]. Condition Based Maintenance implies acquisition, processing, analysis and interpretation of data and the selection of proper maintenance actions. This is achieved using condition monitoring systems $[27,28]$. Thereby, CBM is presented as a useful technique to improve not only the maintenance but the safety of the equipments. Byon and Ding [14] or McMillan and Ault [50] have demonstrated its successful application in wind turbines, making the CBM 
one of the most employed strategies in this industry. Another example of the maintenance evolution is the Reliability Centred Maintenance. It is defined as a process to determine what must be done to ensure that any physical asset works in its operating context [71]. Nowadays it is the most common type of maintenance for many industrial fields [25, 26] and it involves maintenance system functions or identifying failure modes among others maintenance tasks [52].

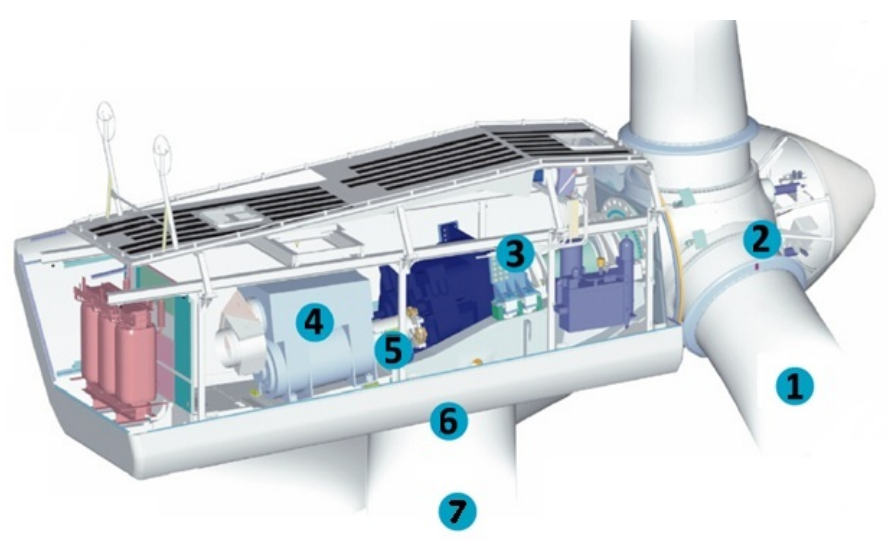

Figure 1. Main parts of a turbine: (1) blades, (2) rotor, (3) gearbox, (4) generator, (5) bearings, (6) yaw system and (7) tower [36].

\subsection{Condition Monitoring applied to Wind Turbines}

Condition Monitoring systems operate from different types of sensors and signal processing equipments. They are capable of monitoring components ranging from blades, gearboxes, generators to bearings or towers. Monitoring can be processed in real time or in packages of time intervals. The procurement of data will be critical to determine the occurrence of a problem and determine a solution to apply. Therefore, the success of a Condition Monitoring system will be supported by the number and type of sensors used and the signal collection and processing.

Any element that performs a rotation is susceptible of being analysed by vibration. In the case of the wind turbines, vibration analysis is mainly specialized in the study of gearboxes [48, 49] and bearings [81] [85]. Different types of sensors will be required depending on the operating frequency: position transducers, velocity sensors, accelerometers or spectral energy emitted sensors.

Acoustic emissions (AE) describe the sound waves produced when a material undergoes stress as a result of an external force [35]. They can detect the occurrence of cracks in bearings [84] and blades [91] in earlier stages. 
Ultrasonic tests evaluate the structural surface of towers and blades in wind turbines [22] [24]. Consistent with some other techniques, it is capable of locating faults safely.

Oil analysis may determine the occurrence of problems in early stages of deterioration. It is usually a clear indicator of the wearing of certain components. The technique is widely used in the field of maintenance, being important for gearboxes in wind turbines [47].

Thermographic technique is established for monitoring mainly electrical components [72]; although its use is extended to the search of abnormal temperatures on the surfaces of the blades [64]. Using thermography, hot spots can be found due to bad contacts or a system failure. It is common the introduction of online monitoring systems based on the infrared spectrum.

There are techniques that not being so extended, are also used in the maintenance of wind turbines. In many cases, their performance is heavily influenced by the costs or their excessive specialization, making them not always feasible. Some examples are strain measurements in blades [68]; voltage and current analysis in engines, generators and accumulators [67]; shock pulse methods detecting mechanical shocks for bearings [13] or radiographic inspections to observe the structural conditions of the [61].

\subsection{Signal processing methods}

\section{Fast Fourier Transform (FFT)}

The FFT converts a signal from the time domain to the frequency domain. The use of FFT also allows its spectral representation [56]. Each frequency range is framed into a particular failure state. It is very useful when periodic patterns are searched [5]. Vibration analysis also provides information about a particular reason of the fault origin and/or its severity [43]. There is extensive literature demonstrating the development of the method for rolling elements. The FFT of a function $f(x)$ is defined as [12]:

$$
\int_{-\infty}^{\infty} f(x) e^{-2 i \pi x s} d x
$$

This integral, which is a function of s, may be written as $F(s)$. Transforming $F(s)$ by the same formula, equation (2) where $F(s)$ is the Fourier transform of $f(x)$ is obtained.

$$
\int_{-\infty}^{\infty} f(s) e^{-2 i \pi \omega s} d s
$$

There are a considerable number of publications regarding the diagnosis of faults for rolling machinery that justifies the models and patterns based on the Fast Fourier Transform. Misalignment is one of the most commonly observed faults in rotating machines, being the second most common malfunction after unbalance. It may be present because of improper machine assembly, thermal distortion and asymmetry in the applied load. Misalignment causes reaction forces in couplings that are the major cause of machinery vibration. Some authors evaluated numerically the effect of coupling misalignment and suggested the occur- 
rence of strong vibrations at twice the natural frequency [70] [95], although rotating machinery can excite vibration harmonics from twice to ten harmonics depending on the signal pickup locations and directions [53].

Faults do not have a unique nature and most of the time, problems on a smaller scale are linked, e.g. in the case of misalignment, when an angular misalignment is studied, parallel misalignment (minor fault) needs to be take into account. Al-Hussain and Redmond reported vibrations for parallel misalignment at the natural frequency from experimental investigations [4].

To facilitate the diagnosis in rolling elements, some companies and researchers tabulate the most common failure modes in the frequency domain, so that the analysis can be carried out easier. Thus, the appearance of different frequency peaks determines the existence of developing problems such as gaps, unbalances or misalignments among other circumstances [31].The great advantage of these tables is that the value of the frequency peak is not a particular value and may be adapted to any situation where the natural frequency (or the rotational speed) is known.

Wavelet transform is a time-frequency technique similar to Short Time Fourier Transform although it is more effective when the signal is not stationary. Wavelet transform decompose an input signal into a set of levels at different frequencies [77]. Wavelet transforms have been applied to the fault detection and diagnosis in various wind turbine parts.

A hidden Markov model is a statistical model in which the system being modelled is assumed to be a Markov process with hidden states. A hidden Markov model can be considered as the simplest dynamic Bayesian network [8]. Ocak and Loparo presented the application for the bearing fault detection [57].

They are used when a statistical study is required. In these cases, common statistical, i.e. the root mean square or peak amplitude; to diagnose faults are employed. Other parameters can be maximum or minimum values, means, standard deviations to energy ratios or kurtosis. Moreover, trend analysis refers to the collection of information in order to find a trend.

There are many methods that, as happened with the techniques available for CM, are very specific and therefore they are used for very specific situations. Filtering methods, for example, are designed to remove any redundant information, eliminating unnecessary overloads in the process. Analysis in time domain will be a way of monitoring wind turbine faults as inductive imbalances o turn-to-turn faults. Other methodology, the power cepstrum, defined as the inverse Fourier Transform of the logarithmic power spectrum [92], reports the occurrence of deterioration through the study of the sidebands. Time synchronous averaging, amplitude demodulation and order analysis are other signal processing methodologies used in wind turbines.

\section{Wavelet transform}

The wavelet transform is a method of analysis capable of identifying the local characteristics of a signal in the time and frequency domain. It is suitable for large time intervals, where 
great accuracy is requested at low frequencies and vice versa, e.g. small regions where precision details for a deeper processing are required at higher frequencies [23]. The wavelet transform can be defined as a signal on a temporal base that is filtered successive times and whose average value is zero. These wavelets are irregular and asymmetrical [51]. The transform has many applications in control process and detection of anomalies. It enables to analyse the signal structures that depend on time and scale, being a useful method to characterize and identify signals with spectral features, unusual temporary files and other properties related to the lack of stationary. When the frequency range corresponding to each signal is known, the data can be studied in terms of time, frequency and amplitude. Therefore it is possible to see which frequencies are in each time interval, and may even reverse the wavelet transform when it is necessary. Previously to the wavelet transform, the FFT was able to work with this type of signals in the frequency domain but without great resolution in the time domain [38].

The wavelet transform of a function $f(t)$ is the decomposition of $f(t)$ in a set of functions and $\psi_{s, \tau}(t)$, forming a base. It is defined as [88] [66]:

$$
W_{f}(s, \tau)=\int f(t) \psi_{s, \tau}^{*}(t) d t
$$

Wavelets transforms are generated from the translation and scale change from a same wavelet function $\psi(t)$, called mother wavelet, which is given by equation (4):

$$
\psi_{s, \tau}(t)=\frac{1}{\sqrt{s}} \psi\left(\frac{t-\tau}{s}\right)
$$

where $s$ is the scale factor, and $\tau$ is the translational factor.

The wavelets $\psi_{s, \tau}(t)$ generated from the same mother wavelet function $\psi(t)$ have different scale $s$ and location $\tau$, but the same shape. Scale factors are always $s>0$. The wavelets are dilated when the scale $s>1$ and contracted when $s<1$. Thus, the changing of the value $s$ can cover different ranges of frequencies. Large values for the parameter $s$ correspond to lower frequencies ranges or a large scale for $\psi_{s, \tau}(t)$. Small values of $s$ correspond to lower frequencies ranges or very small scales.

The wavelet transform can be continuous or discrete. The difference between them is that the continuous transform provides more detailed information but consuming more computation time while the discrete signal is efficient with fewer parameters and less computation time [17]. The Discrete Wavelet Transform coefficients are a group of discrete intervals of time and scales. These coefficients are used to formalize a set of features that characterize different types of signals. Any signal can be divided into low frequency approximations $(A)$ and high frequency details $(D)$. The sum of $A$ and $D$ is always equal to the original signal. The division is done using filters (Figure 2). 


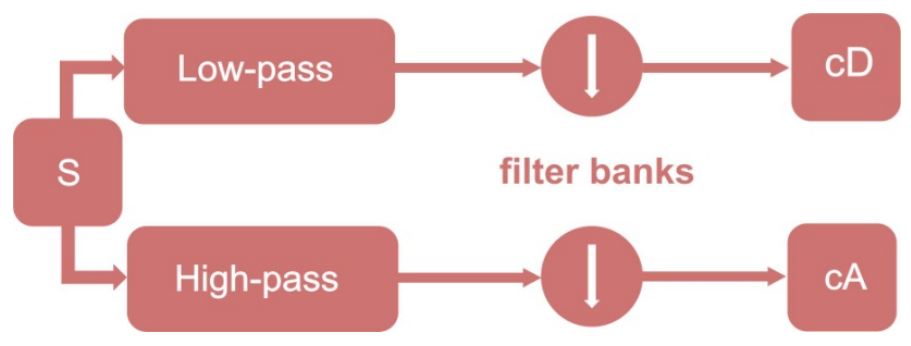

Figure 2. Decomposition diagram.

To reduce the computational and mathematical costs due to duplication of data, a sub-sampling is usually performed, containing the half of the collected information from $A$ and $D$ but without losing information. It is common to accompany this information with a graphical representation where the original signal is divided in low pass filters and high pass filters [15]. When the signals are complex, the decomposition must be to further levels and it is not sufficient with two frequency bands. From this need, multilevel filters appear. Multilevel filters repeat the filtering process iteratively with the output signals from the previous level. This leads to the so called wavelet decomposition trees (Figure 3.) [2]. By decomposing a signal in more frequency bands, additional information is obtained. A suitable branch to each signal is highly recommended as more decompositions do not always mean higher quality results.

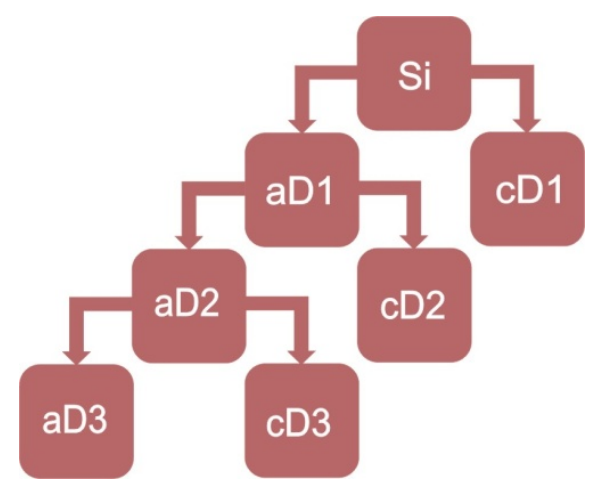

Figure 3. Wavelet decomposition tree.

The calculation of the Continuous Wavelet Transform starts for an initial time and a scale value. The result of multiplying the two signals is integrated into the whole space of time. Subsequently, this integral is multiplied by the inverse of the square root scale value, obtaining a transformed function with a normalized energy. This process is iterative until the end of the original signal is reached and must be repeated for all the values of scale that sweep the frequency range to be studied. 


\subsection{Wavelet families}

The concept of wavelet has emerged and evolved during the last decades. Though new families of wavelet transforms are rapidly increasing, there are a number of them that have been established with more strength over time. In most situations, the use of a particular family is set by the application.

Daubechies wavelets are the most used wavelets, representing the foundations of wavelets signal processing and founding application in Discrete Wavelet Transform. They are defined as a family of orthogonal and smooth basis wavelets characterized by a maximum number of vanishing moments. The degree of smoothness increases as long as the order is higher. Daubechies wavelets lead to more accurate results in comparison to others wavelet types and also handle with boundary problems for finite length signals in an easier way [58] [29] [60] [94]. Wavelets have not an explicit expression except for order 1, which is the Haar wavelet. The inability to present a wavelet equation by a particular formula will be the general trend for almost all types of wavelet families [76].

As above mentioned, Haar wavelets are Daubechies wavelets when the order is 1 . They are the simplest orthonormal wavelets. The main drawback for Haar wavelets is their discontinuity as a consequence of not solving breaking points problems for its derivates. The Haar transform is one of the earliest examples of a wavelet transform and it is supported by a function is an odd rectangular pulse pair [33]. Haar functions are widely used for applications as image coding, edge extraction and binary logic design and are defined as [46] [41] [34] [30]:

$$
H(t)=\left\{\begin{array}{cc}
1 & 0 \leq t<\frac{1}{2} \\
-1 & \frac{1}{2} \leq t<1 \\
0 & \text { elsewhere }
\end{array}\right.
$$

The main advantages of the Haar wavelet are its accuracy and fast implementation compared with others methods, its simplicity and small computational costs, and its capacity for solving boundaries problems [87].

Symlet wavelet transform is an orthogonal wavelet defined by a scaling filter (a low-pass finite impulse response filter of length $2 \mathrm{~N}$ and sum 1 ). Symlet wavelet transform is sometimes called SymletN, where $N$ is the order. Symlet wavelets are near symmetric. Furthermore, they have highest number of vanishing moments for a given width [7].

Coiflet wavelets are a family of wavelets whose main characteristics are similar to the Symlet ones: a high number of vanishing moments and symmetry. Coiflet family is also compactly supported, orthogonal and capable to give a good accuracy when the original signal has a distortion. The Coiflet wavelets are defined for 5 orders [18]. 
Biorthogonal wavelets have become very popular because of its versatility, being capable of supporting symmetric or antisymmetric signals. They perform very well under certain boundaries conditions [97]. Moreover the Biorthogonal wavelet transform is an invertible transform. They have two sets of lowpass filters for reconstruction, and highpass filters for decomposition [32].

Along with the Haar wavelets, the Meyer family is one of the exceptions that can be represented by an equation. The Meyer wavelets have numerous applications in the theory of functions, solving differential equations, signal processing, etc. [39]. Meyer family has not compact support being this one of its drawbacks. It is defined by equation (6) [44]:

$$
\left.\lambda(\omega)\right|_{[0, \infty]}= \begin{cases}\frac{\pi}{4}+\theta(\omega-\pi), & \omega \in\left[\frac{2 \pi}{3}, \frac{4 \pi}{3}\right], \\ \frac{\pi}{4}+\theta\left(\frac{\omega}{2}-\pi\right), & \omega \in\left[\frac{4 \pi}{3}, \frac{8 \pi}{3}\right], \\ 0, & \omega \in\left[0, \frac{2 \pi}{3}\right] \cup\left[\frac{8 \pi}{3},+\infty\right],\end{cases}
$$

where $\theta(\omega)$ is a continuously and differentiable function equal to $\frac{\pi}{4}$ for $\omega \geq \frac{\pi}{3}$.

\subsection{Wavelet transform applications}

The use of the wavelet transform has been developed over the past two decades focused on the process diagnosis and instrumentation. In 1990, Leducq introduces them in the analysis of hydraulic noise for a centrifugal pump [45]. Later other authors demonstrates its usefulness for the detection of mechanical failures and the health monitoring control in gears [74] [11] [90] [21] [82] [80]. Cracks in rotors [1], structures [73] [63] [89] [10] or composite plates [75] has been another exploitation source for wavelet transforms. In 1994, Newland researches on their properties and applications, and coins the term harmonic wavelet. Harmonic wavelets are used for ridge and phase identification in signals [54]. The results showed that the cracks found reduced the rotor speed. The effectiveness of wavelets has also been compared with the envelope detection methodology in the diagnosis of faults in the bearings, obtaining results in shorter time analysis [85].

Due to its good analytical skills in time regarding the frequency, wavelet transform is a guarantee of success in the study of transient processes. Chancey and Flowers [16] managed to discover a relation between vibration patterns and the coefficients of a wavelet. Kang and Birtwhistle [40] or Subramanian, Badrilal and Henry [78] developed techniques to find problems in power transformers. Yacamini [96] proposed a method to detect torsional vibrations in engines and generators from the stator currents.

At present, the development of techniques associated to the scopes mentioned previously are still being implemented but others wavelet transforms purposes are emerging, such as classification of linear frequency modulation signals for radar emitter recognition [83] or ap- 
plications to damages caused by corrosion in chemical process installations [86]. As follow there is an explanation for some of the most examined in the scientific literature.

The application of wavelets transforms in wind turbines focuses on the implementation of adaptive controllers for wind energy conversion systems. Wavelet transform is capable of providing a good and quick approximation. The drivers studied under different noise levels achieved higher performances [69]. Other works study the monitoring and diagnosis of faults in induced generators with satisfactory results. In these cases a combination of DWTs, accompanied by statistical data and energy is proposed. The use of decomposed signals spectral components is other highly interesting technique of study. Its harmonic content has suitable characteristics to be employed in fault diagnosis as an alternative to conventional methods [3].

Rolling bearing plays an important role in rotating machines. The choice of a particular wavelet family is crucial for the maintenance and fault diagnosis. The location of peaks on the vibration spectrum can identify a particular fault. Wavelet decomposition trees are a useful tool for this identification. The mean square error extracted from the terminal nodes of a tree reports the failure and its size [17]. There are also studies focused on determining what type of wavelet is suitable for bearing maintenance [79].

The wavelet transform is a good signal analysis method when a variation of time but not of space exists. The analysis provides information about the frequency of the signal, being a solution for the engine failure detection. There are detection algorithms that identify the presence of a fault in working condition and are ahead of the shutdown of the system, reducing costs and downtimes [19] [20]. These algorithms are independent of the type of engine used. Other studies in this field, present methods to detect imbalances in the stator voltage of a three phase induction motor. The wavelet transform of the stator current is analysed. Computationally, these methods are less expensive than other existing and can detect faults in an early stage. In the same vein, monitoring fatigue damage has been studied [65].

\section{Condition Monitoring for engine-generator mechanism}

A novel approach for Condition Monitoring based on wavelet transforms is introduced. A system for a mechanism based on an engine and a generator will be shown. It has been designed to represent any similar mechanism located in a wind turbine, generally in the nacelle. These mechanisms are used in cooling devices (generators, gearboxes), electric motors for service crane, yaw motors, pitch motors (depending on the configuration) or pumps (oil, water) according to the sub systems configurations, ventilators, etc (Figure 4).

A set of faults are induced in different experiments: ski-slope faults, misalignment faults, angular misalignment faults, parallel misalignment faults, rotating looseness faults and external noise faults. Pattern recognition is obtained from the extraction of vibration and acoustic signals. A Fault Detection and Diagnosis method is developed from the patterns of these signals. In order to recognize the patterns, three basic steps have been followed [37]: 
1. The data acquisition on the testing bench (Figure 5).

2. The extraction of the features of the experiment using specific algorithms.

3. A decision-making.

A classification has been done to obtain the optimal pattern recognitions employing the data from Fast Fourier Transform and wavelet transforms applied to the vibrations and sounds signals respectively.

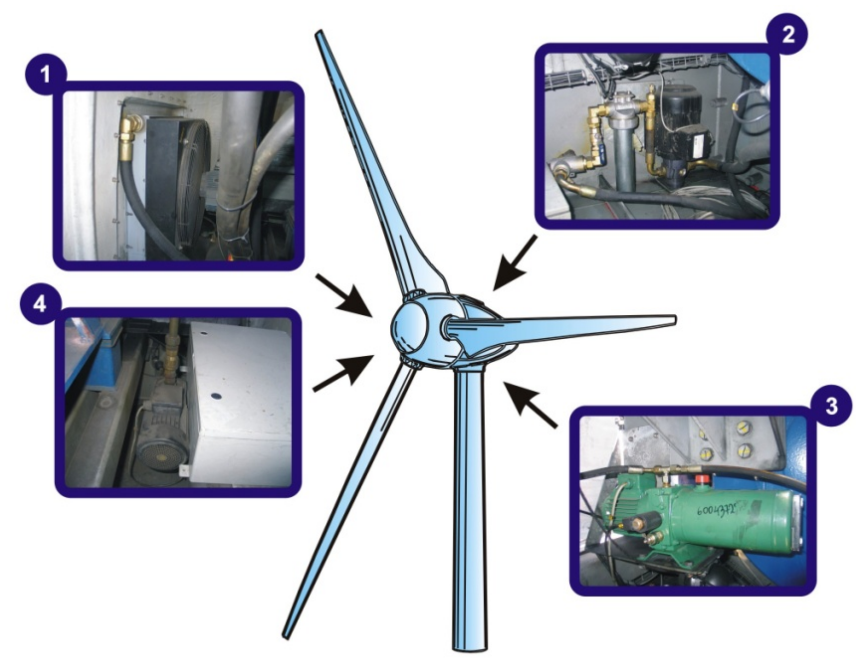

Figure 4. Different locations of a wind turbine where the CM can be used: (1) fans, (2) gear oil pump, (3) oil pump for brake and (4) water cooling pump.

\subsection{Case study}

The experiments were made on a mechanism consisting of an engine and a generator linked by an elastic coupling joint. The sensors employed were a current sensor, an ambient temperature sensor, another temperature sensor located in strategic points of the mechanism, a vibration sensor; and a sound sensor (microphone). The data obtained by these sensors are stored in a data acquisition board, except for the vibration which is collected directly with a vibrometer. The software employed was LabView and specific software for vibration provided by the manufacturer Kionix. The speed of the engine and its associated frequency were set by a frequency variator, and the energy is dispelled using a resistive element.

The allocation of the vibration measurements were: two points for the engine and two for the generator. Points of selection were located at the end of each machine and as close as possible to the axis which is the main rotational element of the mechanism (Figure 6). 

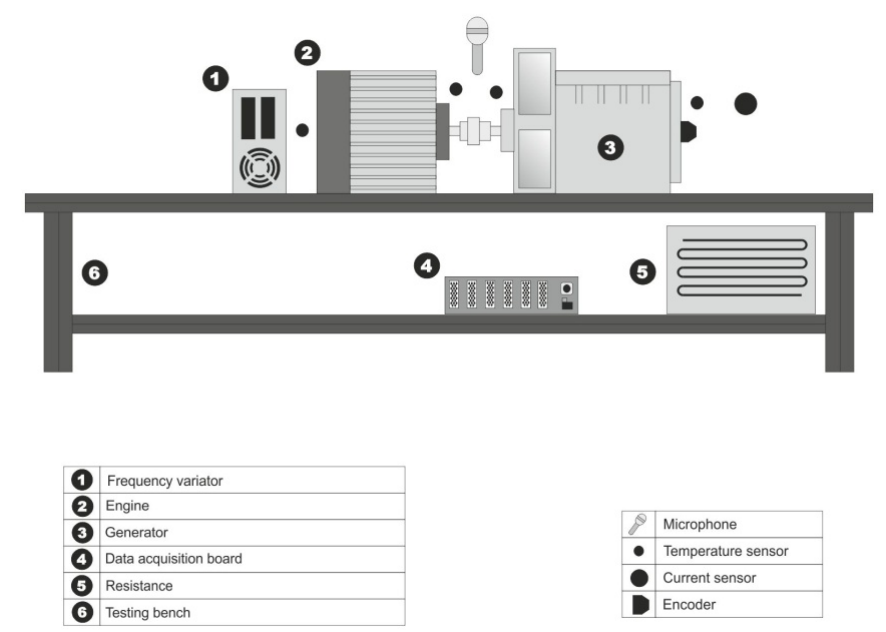

Figure 5. Experimental mechanism.

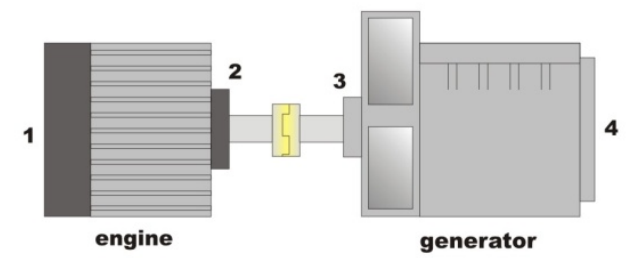

Figure 6. Measuring points.

The experiments were completed for an average time of 10 seconds each one, and every experiment was repeated 3 times. Therefore, for each experiment 12 measurements of temperatures, currents, sound, velocities and vibrations were taken (Figure 7). In the case of vibration, the vibrometer is capable of storing samples for the ' $x$ ', ' $y$ ' and ' $z$ ' axis, in addition to a total measurement for the point studied (Figure 8).

The experiments were carried out in order to identify couplings and misalignments in different degrees. The engine has 4 rubber clamping (silemblocks), while the generator has 3 rubbers clamping. The silemblocks were located at the ends, having two on the right side of the engine and two on the left side. The generator has them placed in a triangle, two in the area closest to the coupling and one at the end. The first experiment recorded under free 
fault conditions, and the rest of experiments were performed when the silemblocks were removed from the engine and the generator in order to create the different degrees of decoupling (Figure 9).

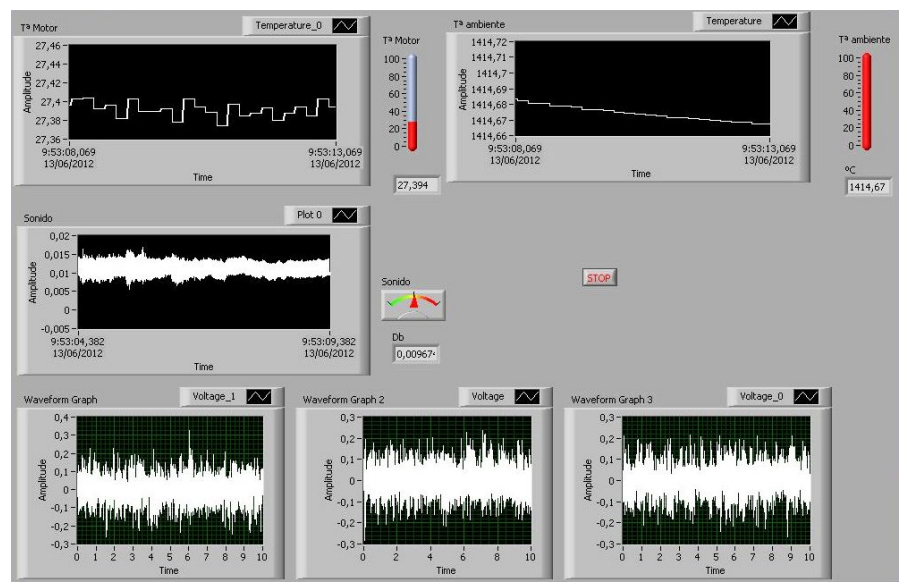

Figure 7. Data collection in LabView.

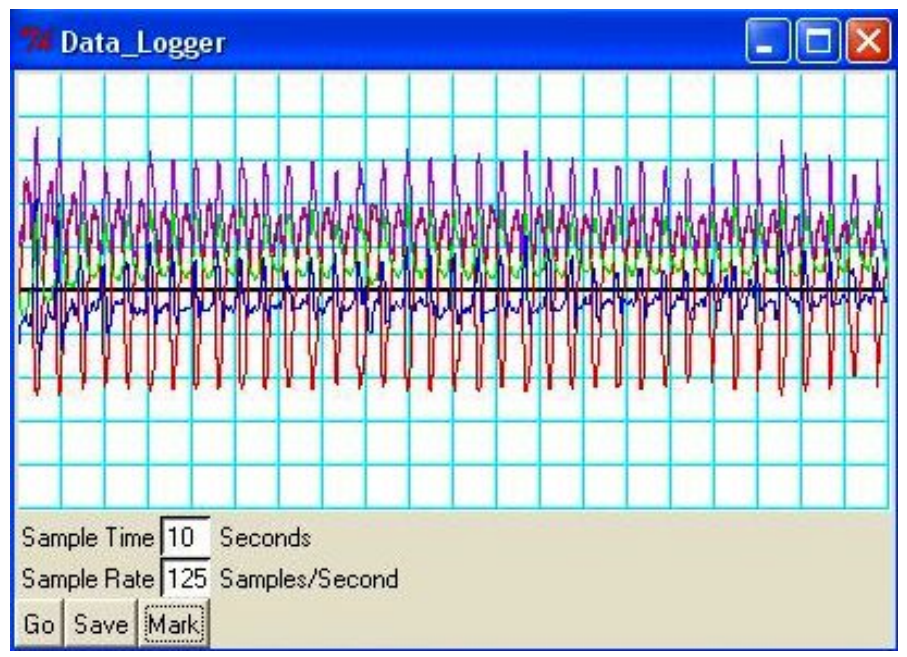

Figure 8. Data collection with Kionix software (vibration).

The rotational speed is $1500 \mathrm{rpm}$, i.e. $25 \mathrm{~Hz}$. In order to do an analysis above the natural frequency, the number of samples was increased from $25 \mathrm{~Hz}$ to $125 \mathrm{~Hz}$, being $25 \mathrm{~Hz}$ the default samples. This guarantees a range 5 times bigger than the natural frequency of the engine. 


\begin{tabular}{|c|c|c|}
\hline Experiment & Type of experiment & Data set \\
\hline 1 & Free fault conditions & From 1 to 12 \\
\hline 2 & Misalignment removing silemblocks from the right side of the engine & From 13 to 24 \\
\hline 3 & $\begin{array}{l}\text { Misalignment removing silemblocks from the right side and the front } \\
\text { left one of the engine }\end{array}$ & From 25 to 36 \\
\hline 4 & Generation of resistance in the coupling & From 37 to 48 \\
\hline 5 & $\begin{array}{l}\text { Misalignment removing the silemblock from the right side of the } \\
\text { generator }\end{array}$ & From 49 to 60 \\
\hline 6 & $\begin{array}{l}\text { Misalignment removing } 2 \text { silemblocks near to the coupling in the } \\
\text { generator }\end{array}$ & From 61 to 72 \\
\hline 7 & $\begin{array}{l}\text { Misalignment removing the silemblock from the right side of the } \\
\text { generator and one from the left side of the engine }\end{array}$ & From 73 to 84 \\
\hline 8 & Use of a rigid coupling & From 85 to 96 \\
\hline
\end{tabular}

Table 1. Experiments (1500 rpm).

The FFT of each signal has been developed in Matlab. An algorithm that allows the comparison of two signals for a given frequency was created. The main purpose is to compare pattern conditions with the signals of the rest of experiments that represent a fault and to analyse the peaks found in the natural frequency and its multiples. In some cases it is important to analyse the area located below the natural frequency. Another advantage of the program is that it is possible to obtain the amplitude values for a certain frequency range (Figure 10). With a click on a particular peak, the program provides the data.
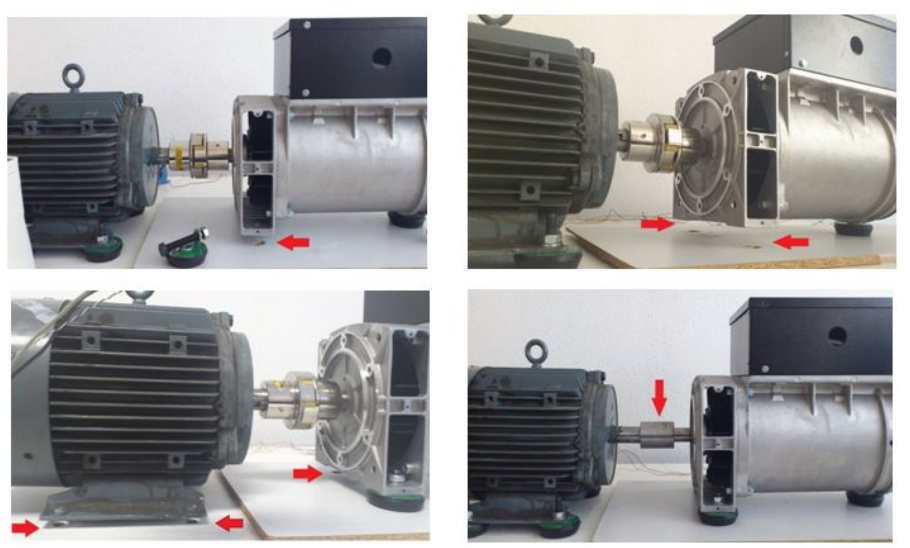

Figure 9. Misalignments induced removing silemblocks from the engine and the generator and experimentation with a rigid coupling. 
Values for $25 \mathrm{~Hz}$ (natural frequency or 1X), $50 \mathrm{~Hz}(2 X), 75 \mathrm{~Hz}(3 \mathrm{X})$ and $100 \mathrm{~Hz}(4 \mathrm{X})$ have been taken into account. Frequencies above these values have been discarded.

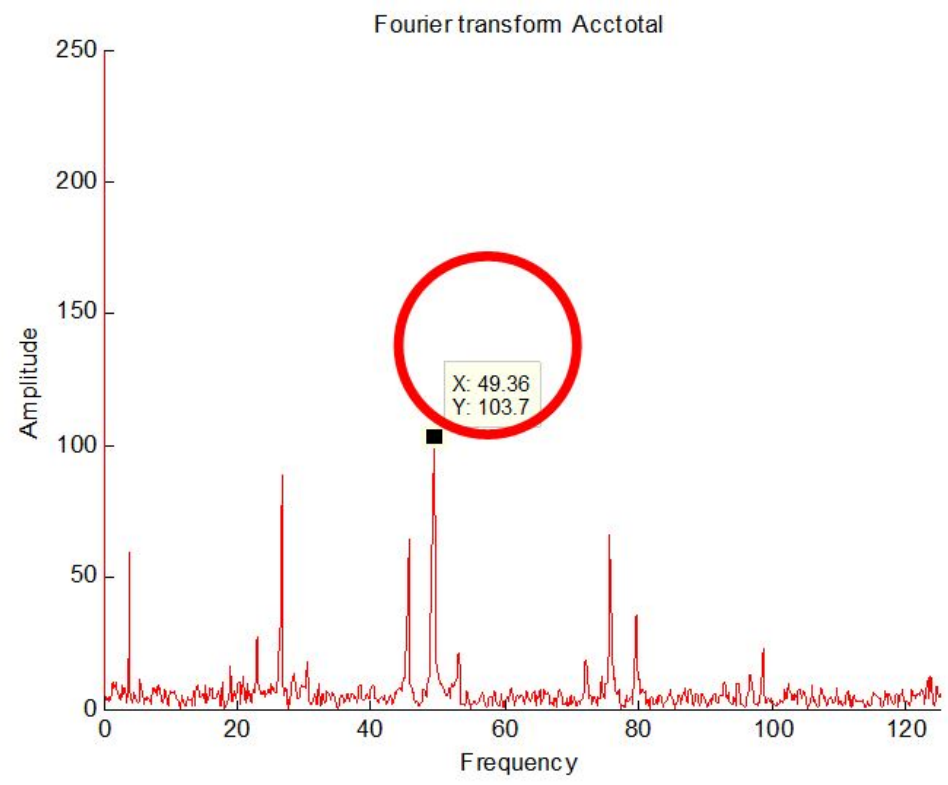

Figure 10. FFT of a vibration signal.

\subsection{Vibration diagnosis and results}

The most common spectrums for engine-generator mechanisms are presented. Examples based on the experiments held are shown.

Ski-slope fault

A ski-slope fault appears when the spectrum begins at a high level and then it goes down slowly (Figure 11). A ski-slope shows a problem with the quality of the sensor. Sometimes it happens because the sensor has experienced a transient during the measurement process. The transient may be mechanical, thermal or electrical.

Misalignment faults

Misalignment fault appears when the centrelines of coupled shafts do not coincide. If the misaligned shaft centrelines are parallel but not coincident, then the misalignment is a parallel misalignment. If the misaligned shafts meet at a point but they are not parallel, the misalignment is angular. Most of the cases are a combination of them. The diagnosis is based on dominant vibration from the natural frequency $(1 X)$ at twice the rotational rate $(2 X)$, with increased rotational rate levels $(3 X, 4 X$, etc.) acting in the axial, vertical or horizontal directions. 
Angular misalignment fault

Angular misalignment fault produces a bending moment on both shafts and this generates a strong vibration at $1 X$, and some others at $2 X$ and $3 X$ for the axial direction. There will also be strong radial components for vertical and horizontal directions (Figure 11).

\section{Parallel misalignment fault}

Parallel misalignment fault produces a shear force and a bending moment on the coupled end of each shaft. High vibration levels at $2 X$ as well as $1 \mathrm{X}$ are produced in the radial direction. Most often the $2 X$ component is higher than $1 X$. Depending on the coupling, there can be $3 \mathrm{X}$ or $4 \mathrm{X}$, even reaching $8 \mathrm{X}$ when the misalignment is severe (Figure 11).

Rotating looseness fault

Rotating looseness fault will create harmonics or sub-harmonics every $0.5 X$. Even $1 / 3$ order harmonics are possible (Figure 11).

\section{External noise fault}

It is very common to find a peak in a spectrum that is difficult to analyse. This happens because of the vibration from another machine or process. The peak will typically be at a nonsynchronous frequency (Figure 11). External noise can be verified stopping the machine (or varying the speed) and seeing if the vibration is still present or checking local machines for the same frequency source.
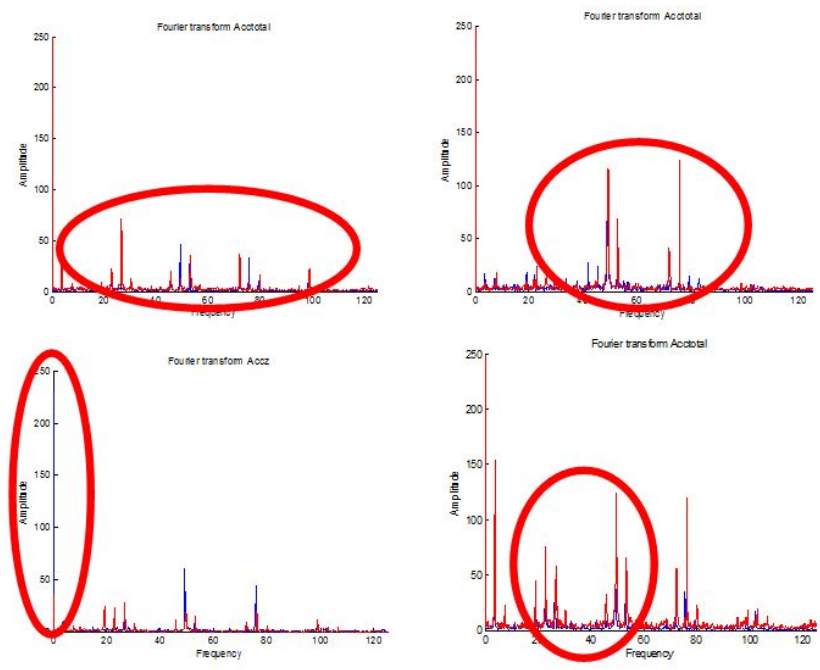

Figure 11. a) Angular misalignment fault (red) and pattern condition (blue), (b) parallel misalignment fault (red) and pattern condition (blue), (c) ski-slope fault (blue) and pattern condition (red) and (d) rotating looseness (blue); and external noise (red). 


\subsection{Vibration results}

As a rule, the natural frequency $(1 X)$ has been kept as the reference. Following the same nomenclature, the peaks at $50 \mathrm{~Hz}, 75 \mathrm{~Hz}$ and $100 \mathrm{~Hz}$ have been named 2X, 3X and 4X.

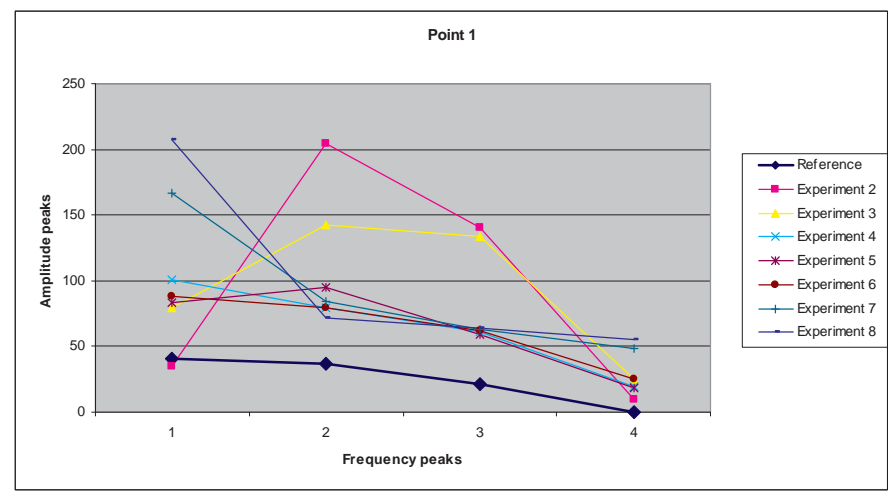

Figure 12. Vibration for point 1.

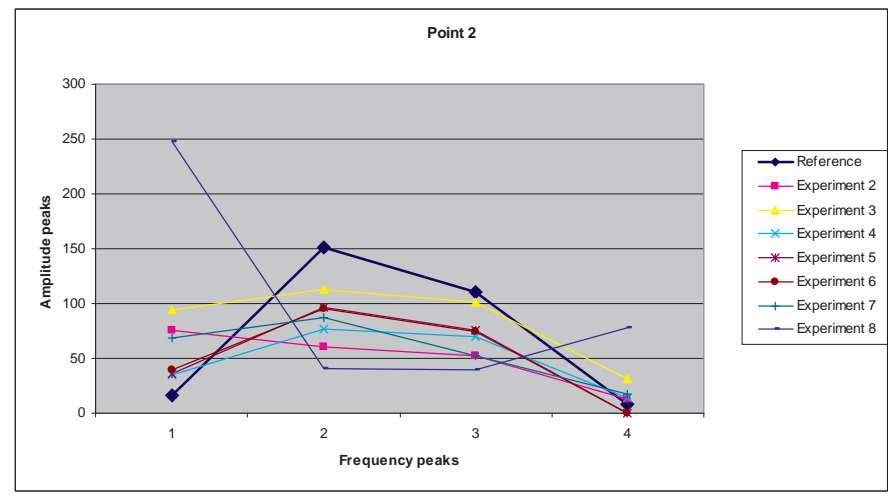

Figure 13. Vibration for point 2.

Vibration patterns are different for the four operating points. It has been detected that the natural frequency, regardless of its amplitude, tends to predominate in the experiments associated with the end points of the set (Figures 12 and 15). Additionally, the generator's closest point to the coupling also has a similar pattern (Figure 14). The second point differs from the rest, yielding most predominant peaks from the frequency at $50 \mathrm{~Hz}$ (Figure 13). To make the vibration analysis, it must be taken into consideration not only the appearance of peaks, but also the amplitude. The same diagnosis for two experiments can vary its amplitude depending on the severity of the faults found. The main symptoms appear when peaks at $0.5 \mathrm{X}$, 
$1 X, 2 X$ and $3 X$, sidebands and noise sources are detected. When a failure is studied at an advanced stage, peaks at $4 \mathrm{X}$ are noticeable (case of rigid coupling).

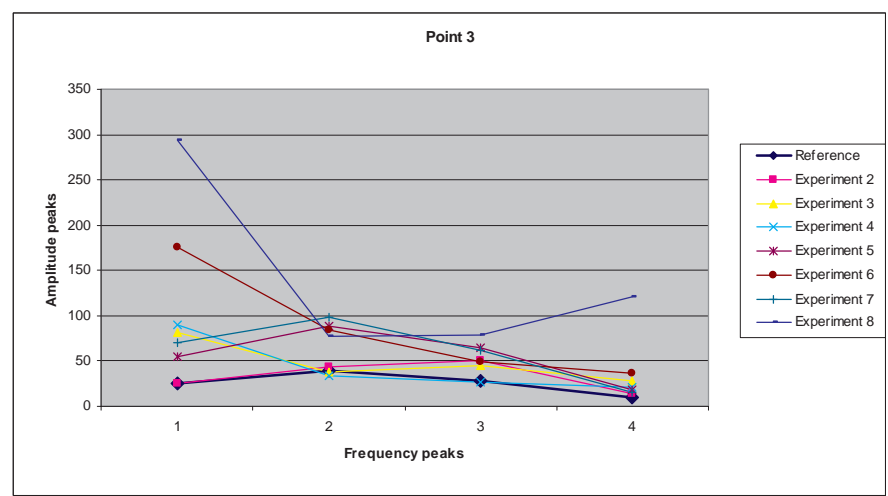

Figure 14. Vibration for point 3.

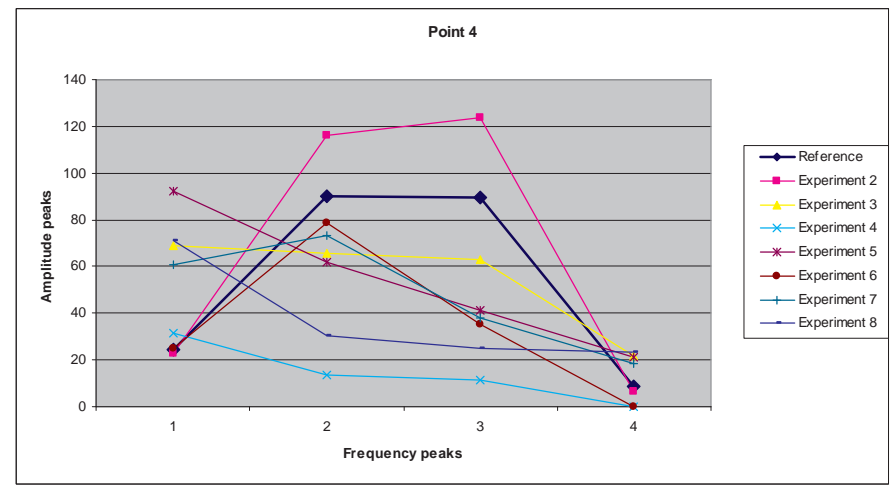

Figure 15. Vibration for point 4.

The diagnosis of the experiments reveals that the mechanism has a minor looseness which causes the appearance of a high peak at the natural frequency in some cases, even under free fault conditions. This looseness appears because the engine and the generator are not anchored directly to the test bench. The assembly was done on a surface that has facilitated the removal of the silemblocks when the experiments required it, e.g. to create different degrees of misalignment. On the other hand, this action expands the vibration intentionally because in this way it is closer to the actual behavior of the nacelle. These frequency peaks change their trend in $1 \mathrm{X}$ as long as the study advances from the end of the engine to the generator. 
From point 2, the peak at frequencies as $2 \mathrm{X}$ and $3 \mathrm{X}$ becomes more significant and sometimes exceed the amplitude of the natural frequency.

The results for experiment 8 are also remarkable. The rigid coupling added causes a severe looseness and vibration. The growth of a frequency at $4 \mathrm{X}$ and a constant noise over the spectrum is observed. Although it is usual to find sidebands, peaks below $1 \mathrm{X}$ and high frequency peaks for all this type of experiments, this feature is unique to this last experiment. Initially, a similar diagnosis for cases 1, 4 and 8 was expected, but the behavior has been slightly different for this reason.

\subsection{Wavelet transform processing approach and results}

Wavelet transforms were employed to analyse the sound signals. As for the Fast Fourier Transform, an algorithm has been written with Matlab. This program plots and compares two signals. Data has been transformed in 5 decompositions named $a_{4}, d_{4}, d_{3}, d_{2}$ and $d_{1}$, where each of them has an energy rate associated from the original signal (Figure 16). The algorithm also returns a percentage value per decomposition. These values of energy, the decomposition levels attached and the peak amplitudes are examined in order to look for patterns.

Functions in the time domain can be represented as a linear combination of all frequency components present in a signal, where the coefficients are the amount of energy provided by each frequency component to the original signal. The main decomposition is associated with $a_{4}$ (main or mother wavelet) that usually has the highest energy, though it is not always necessarily the case. It has a similar pattern to the original signal. The first $\left(d_{4}\right)$, second $\left(d_{3}\right)$, third $\left(d_{2}\right)$ and fourth $\left(d_{1}\right)$ transformed signals have decreasing energy rates, being $s$ the original signal. Usually $a_{4}$ is the low frequency component of the original signal while $d_{i}$ is the high frequency component, having $d_{1}$ the biggest value.

It is necessary to verify that the experiments performed at $1500 \mathrm{rpm}$ can be extrapolated to other speeds. In the case of wind turbines, most of the engines rotate at speeds close to 3000 $\mathrm{rpm}$. A certain number of tests were done varying from 500 to $3000 \mathrm{rpm}$ (at intervals of 500 $\mathrm{rpm}$ ) in order to ensure the existence of the proportional pattern.

The results showed that regardless of the speeds or the points of study, all the graphical representations for the different decompositions of energy had the same patterns. Figure 17 indicates the existence of a similar behavior where only changes the numerical value. The biggest ones will correspond to the main signals, while the results for decompositions $d_{1}$ and $d_{2}$ are similar.

Data can be studied according to the evolution of a single point along the different experiments or analysing the evolution of the set points for all the experiment. Each row in Figure 18 contains two graphics, one with the amplitude peaks (left) and the other one with the energy distribution of the sound signal (right). The first two graphics correspond to the engine end (point 1). The following two graphics are the closest to the coupling (point 2). The third row belongs to the points of the generator next to the coupling (point 3), and finally, the last two graphics are for the end of the generator (point 4). 

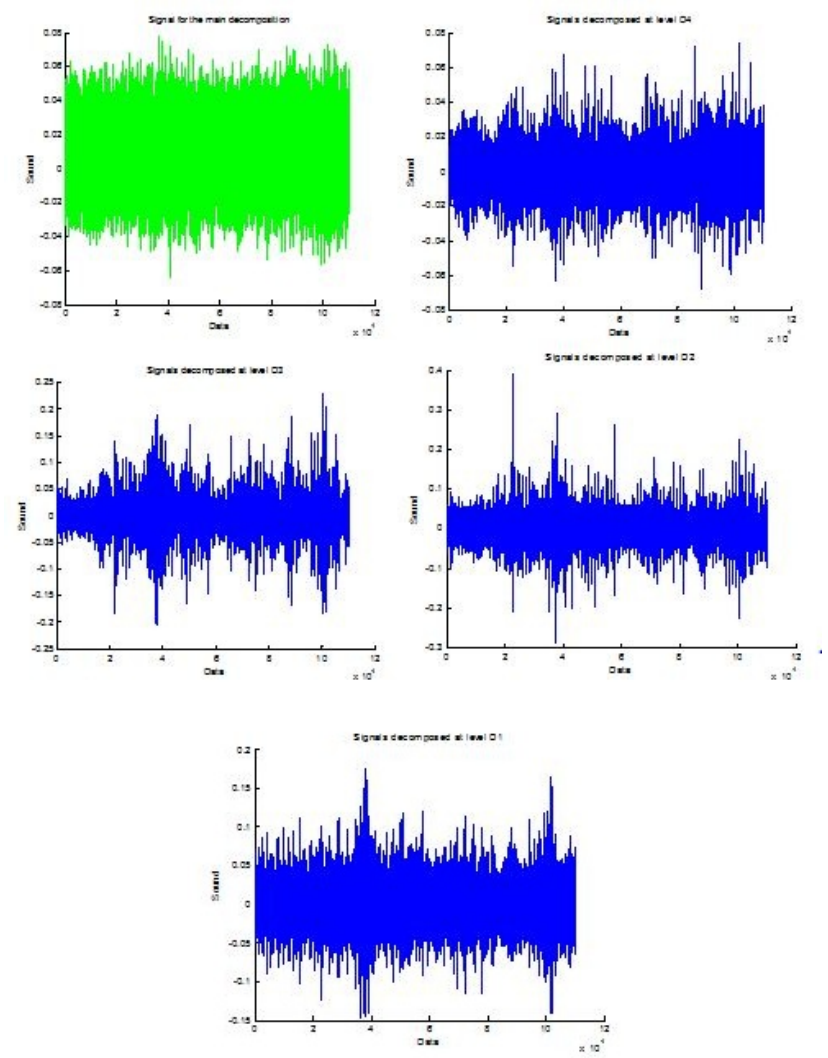

Figure 16. Wavelet decompositions.

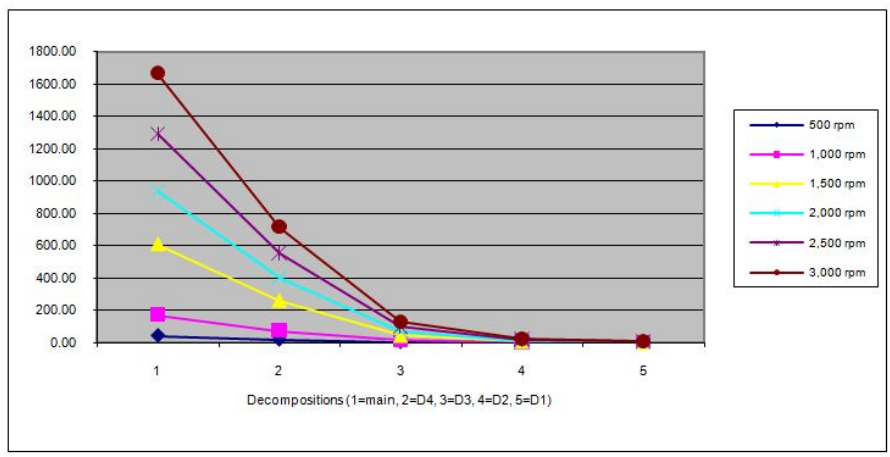

Figure 17. Energies at different rotational speeds. 

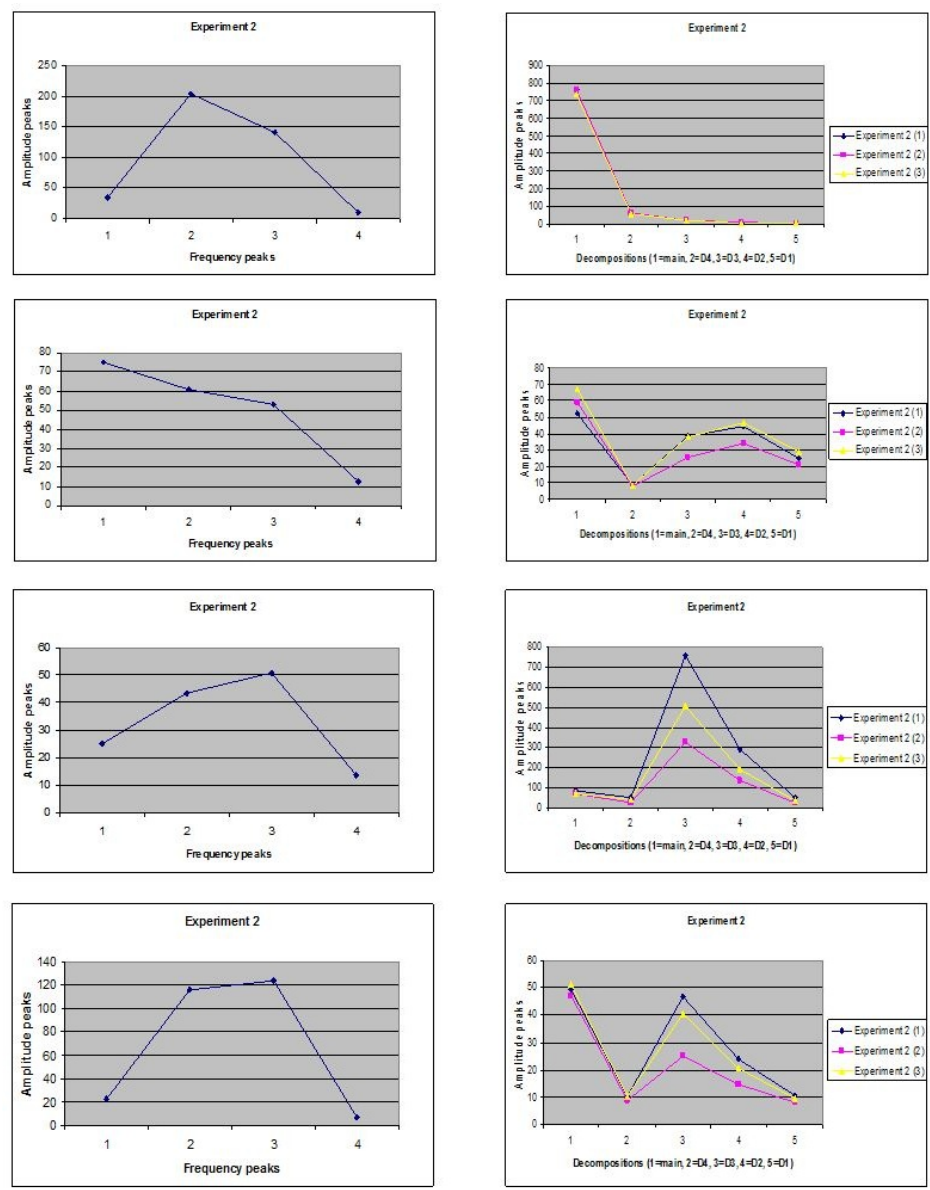

Figure 18. Evolution of the frequency peaks and wavelet energy decompositions for each point in experiment 2.

Based on the distribution of the energy among the 5 different decompositions of every signal, the energy distribution for point 1 , end of the engine-generator set is ruled by an almost similar pattern where each experiment has a maximum of energy in the main signal and a minimum for decomposition $d_{1}$ or $d_{2}$. It means that by performing a decomposition of the signal, the energy has a closest resemblance to the original value, often exceeding $85 \%$ of the total energy, remaining a residual percentage for $d_{1}$ or $d_{2}$. When the experiments are closer to the generator (points 2, 3 and 4), the energy is distributed among the 5 decompositions and not concentrated in the mother wavelet, as it is for point 1.

All the decompositions have been registered with their energy maximum and minimum values and their patterns distribution. An example for 2 experiments is shown in Table 2. 


\begin{tabular}{ccccccr}
\hline Experiment & Main & \multicolumn{1}{c}{$\mathbf{d}_{\mathbf{4}}$} & \multicolumn{1}{c}{$\mathbf{d}_{\mathbf{3}}$} & \multicolumn{1}{c}{$\mathbf{d}_{\mathbf{2}}$} & \multicolumn{1}{c}{$\mathbf{d}_{\mathbf{1}}$} & \multicolumn{1}{c}{ Energy } \\
\hline $\mathrm{A}$ & $17,19 \%$ & $9,10 \%$ & $22,12 \%$ & $24,95 \%$ & $26,63 \%$ & 167,9 \\
\hline $\mathrm{B}$ & $82,32 \%$ & $9,90 \%$ & $5,17 \%$ & $1,77 \%$ & $0,84 \%$ & 311,8 \\
\hline
\end{tabular}

Table 2. Energy distribution for experiments $A$ and $B$.

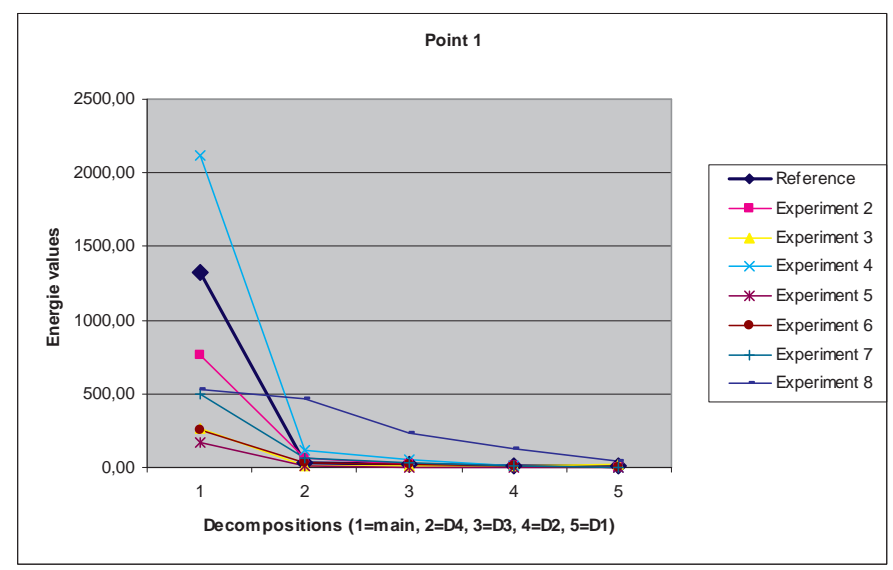

Figure 19. Energy values for point 1.

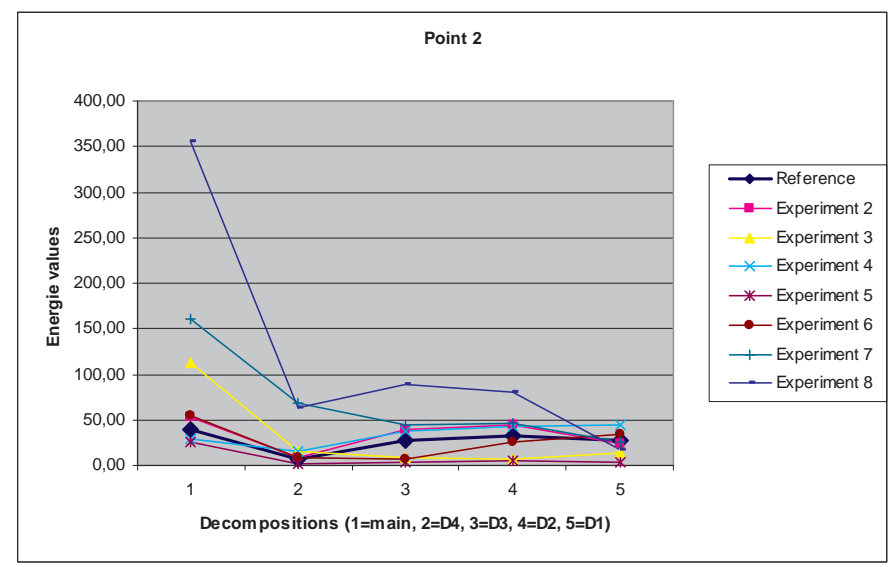

Figure 20. Energy values for point 2 .

Experiment $\mathrm{A}$ is associated to point 2, belonging to the engine and situated close to the coupling. Experiment B, however, is related to point 1, left end of the assembly. Experiment A 
has the maximum percentage of energy in $d_{1}$ and the minimum in $d_{4}$. Furthermore, the experiment $\mathrm{B}$ has its maximum in the main signal and the minimum located in $d_{1}$. The maximum-minimum patterns are $d_{1}-d_{4}$ and main- $d_{1}$ respectively. Numerically, the most compensated distribution of energy is close to the coupling (experiment A - point 2) above mentioned. The patterns main- $d_{1}$ and main- $d_{2}$ appear for all the cases in point 1 . However, the same maximum-minimum distribution is smaller for the points 2, 3 and 4 . Unlike in point 1 , there are different patterns for the 8 experiments in these points. Figures 19, 20, 21 and 22 represent the numerical values of the energy per point and experiment. It must be noted that the numerical values are higher or lower, depending on the type of experiment.

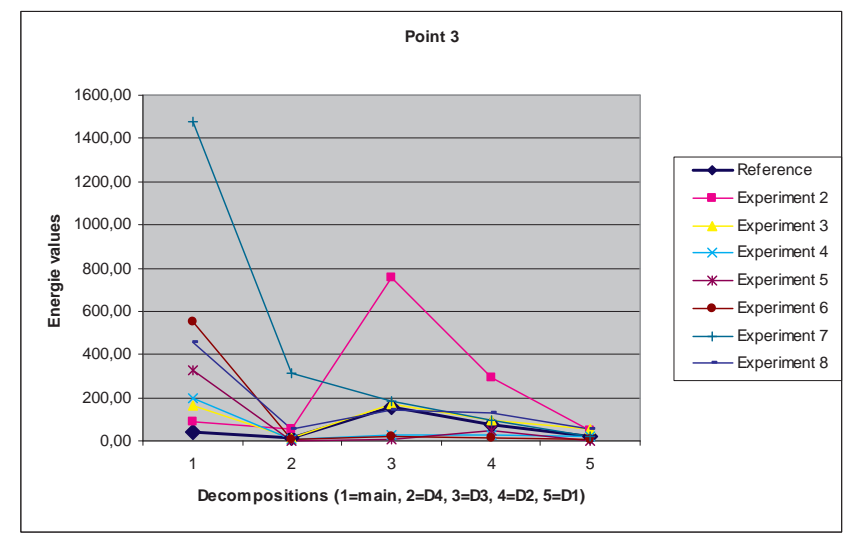

Figure 21. Energy values for point 3.

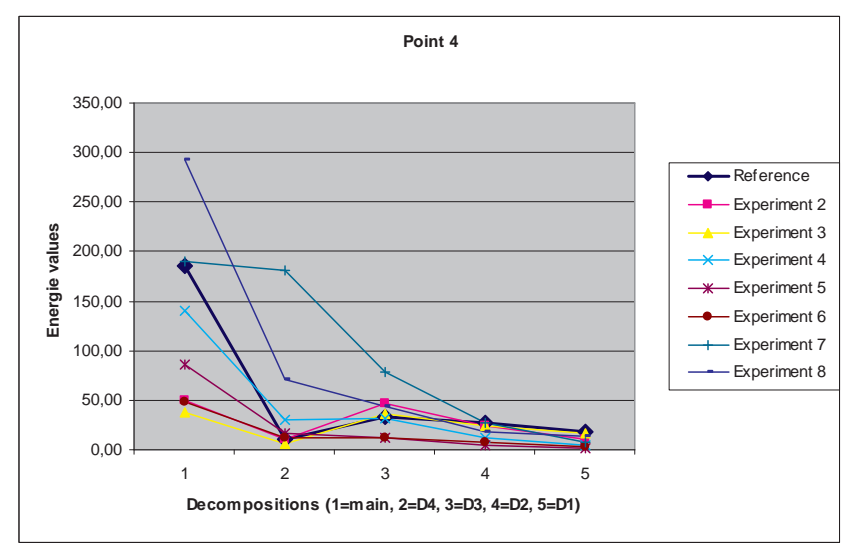

Figure 22. Energy values for point 4. 


\section{Conclusions}

Wind turbines are complex systems that require a high level of reliability, availability, maintainability and safety. This chapter is focused on to guarantee these correct levels for mechanisms used in cooling devices for generators and gearboxes, electric motors for service crane, yaw motors, pitch motors, pumps, ventilators, etc.

The mechanism brake of the engine has been simulated linking a generator by a coupling joint. The signals collected have been:

- Vibration.

- Sound.

- Current.

- Temperature.

- Velocity.

The experiments have been done in working conditions for different points of the mechanism and considering the following failures:

- Misalignment removing silemblocks from the right side of the engine.

- Misalignment removing silemblocks from the right side and the front left one of the engine.

- Induction of resistance in the coupling.

- Misalignment removing the silemblock from the right side of the generator.

- Misalignment removing 2 silemblocks near to the coupling in the generator.

- Misalignment removing the silemblock from the right side of the generator and one from the left side of the engine.

- Using a rigid coupling.

A fault detection and diagnosis model based on the Fast Fourier Transform applied to the vibration signals; together with the wavelet transform applied to sound signals has been developed. The model detects and diagnoses correctly 100\% of the failures considered.

It has been observed that for the outer ends of the engine and the generator, the appearance of a pronounced peak amplitude at the natural frequency or $2 X$ (vibration) was associated to the maximum energy values for the main signal, the most suitable with the original, and minimum values for decomposed signals $d_{1}$ and $d_{2}$ (sound). In contrast, the results obtained close to the coupling did not follow a clear trend as the results were conditioned by the type of experiment. The numerical values of each peak were also taken into account in the establishment of the pattern recognitions, being different for each experiment. The same conclusion was reached for the energy values. Different models and results were expected because 
the objective was not to find similar patterns between different experiments, and the tests were never performed under identical conditions. The objective was to have different vibration patterns and their associated sound models in order to create a catalogue of possible scenarios for predictive maintenance in the mechanisms. Thus, it is possible to extend the range of possibilities to relate the result of an acoustic signal with the frequency domain using the Fast Fourier Transform.

\section{Author details}

Fausto Pedro García Márquez¹, Raúl Ruiz de la Hermosa González-Carrato", Jesús María Pinar Perez ${ }^{1}$ and Noor Zaman²

1 University of Castilla-La Mancha, Spain

2 CCSIT, King Faisal University, Saudi Arabia

\section{References}

[1] Adewusi, S. A., \& Al-Bedoor, B. O. (2001). Wavelet analysis of vibration signals of an overhang rotor with a propagating transverse crack. Journal of Sound and Vibration., 246(5), 777-793.

[2] Aktas, M., \& Turkmenoglu, V. (2010). Wavelet-based switching faults detection in direct torque control induction motor drives. Science, Measurement and Technology., 4(6), 303-310.

[3] Al-Ahmar, E., Benbouzid, M. E. H., \& Turri, S. (2008). Wind energy conversion systems fault diagnosis using Wavelet analysis. International Review of Electrical Engineering., 3(4), 646-652.

[4] Al-Hussain, K. M., \& Redmond, I. (2002). Dynamic response of two rotors connected by rigid mechanical coupling with parallel misalignment. Journal of Sound and Vibration., 249(3), 483-498.

[5] Amidror, I., \& Hersch, R. (2009). The role of Fourier theory and of modulation in the prediction of visible moiré effects. Journal of Modern Optics., 56(9), 1103-1118.

[6] Anon. (2005). Managing the wind: Reducing kilowatt-hour costs with condition monitoring. Refocus., 6(3), 48-51.

[7] Arora, R., Sharma, L., Birla, N., \& Bala, A. (2011). An algorithm for image compression using 2D wavelet transforms. International Journal of Engineering Science $\mathcal{E}$ Technology., 3(4), 2758-2764. 
[8] Baum, L. E., \& Petrie, T. (1966). Statistical inference for probabilistic functions of finite state Markov chains. The Annals of Mathematical Statistics., 37(6), 1554-1563.

[9] Ben-Daya, M. S., \& Duffuaa, A. R. (2009). Handbook of maintenance management and engineering. Springer Verlag London Limited.

[10] Bieman, C., Staszewski, W. J., Boller, C., \& Tomlinson, G. R. (1999). Crack detection in metallic structures using piezoceramic sensors. Key Engineering Materials., 167, 112-121.

[11] Boulahbal, D., Farid, G. M., \& Ismail, F. (1999). Amplitude and phase wavelet maps for the detection of cracks in geared systems. Mechanical Systems and Signal Processing., 13(3), 423-436.

[12] Bracewell, R. (2000). The Fast Fourier Transform and its applications. McGraw Hill Higher Education.

[13] Butler, D. E. (1973). The shock pulse method for the detection of damaged rolling bearings. NDT International., 6(2), 92-95.

[14] Byon, E., \& Ding, Y. (2010). Season-dependent condition-based maintenance for a wind turbine using a partially observed Markov decision process. IEEE Transactions on Power Systems., 25(4), 1823-1834.

[15] Canal, M. R. (2010). Comparison of wavelet and short time Fourier transform methods in the analysis of EMG signals. Journal of Medical Systems., 34(1), 91-94.

[16] Chancey, V. C., \& Flowers, G. T. (2001). Identification of transient vibration characteristics using absolute harmonic wavelet coefficients. Journal of Vibration and Control., $7(8), 1175-1193$.

[17] Chebil, J., Noel, G., Mesbah, M., \& Deriche, M. (2010). Wavelet decomposition for the detection and diagnosis of faults in rolling element bearings. Jordan Journal of Mechanical E Industrial Engineering., 4(5), 260-266.

[18] Chourasia, V. S., \& Mittra, A. K. (2009). Selection of mother wavelet and denoising algorithm for analysis of foetal phonocardiographic signals. Journal of Medical Engineering \& Technology., 33(6), 442-448.

[19] Combastel, C., Lesecq, S., Petropol, S., \& Gentil, S. (2002). Model-based and wavelet approaches to induction motor on-line fault detection. Control Engineering Practice., 10(5), 493-509.

[20] Cusidó, J., Romeral, L., Ortega, J. A., García, A., \& Riba, J. R. (2010). Wavelet and PDD as fault detection techniques. Electric Power Systems Research., 80(8), 915-924.

[21] Dalpiaz, G., Rivola, A., \& Rubini, R. (2000). Effectiveness and sensitivity of vibration processing techniques for local fault detection in gears. Mechanical Systems and Signal Processing., 14(3), 387-412. 
[22] Deshpande, V. S., \& Modak, J. P. (2002). Application of RCM for safety considerations in a steel plant. Reliability Engineering and System Safety., 3(78), 325-334.

[23] Dong, Y., Shi, H., Luo, J., Fan, G., \& Zhang, C. (2010). Application of wavelet transform in MCG-signal denoising. Modern Applied Science., 4(6), 20-24.

[24] Endrenyi, J., Mc Cauley, J., \& Singh, C. (2001). The present status of maintenance strategies and the impact of maintenance on reliability. IEEE Transaction Power System., 16(4), 638-646.

[25] García, F. P., Schmid, F., \& Collado, J. C. (2003). A reliability centered approach to remote condition monitoring. A railway points case study. Reliability Engineering $\mathcal{E}$ System Safety., 80(1), 33-40.

[26] García, F. P., Schmid, F., \& Collado, J. C. (2003). Wear assessment employing remote condition monitoring: A case study. Wear., 2(255), 1209-1220.

[27] García, F. P., Pedregal, D. J., \& Roberts, C. (2010). Time series methods applied to failure prediction and detection. Reliability Engineering \& System Safety., 95(6), 698-703.

[28] García, F. P., Roberts, C., \& Tobias, A. (2010). Railway point mechanisms: Condition monitoring and fault detection. Proceedings of the Institution of Mechanical Engineers, Part F, Journal of Rail and Rapid Transit. Professional Engineering Publishing, 224(1), $35-44$.

[29] Genovese, L., Neelov, A., Goedecker, S., Deutsch, T., Ghasemi, S., Willand, A., Caliste, D., Zilberberg, O., Rayson, M., Bergman, A., \& Schneider, R. (2008). Daubechies wavelets as a basis set for density functional pseudopotential calculations. Journal of Chemical Physics., 129(1), 104-109.

[30] Ghanbari, M., Askaripour, M., \& Khezrimotlagh, D. (2010). Numerical solution of singular integral equations using Haar wavelet. Australian Journal of Basic \& Applied Sciences., 4(12), 5852-5855.

[31] Goldman, P., \& Muszynska, A. (1999). Application of full spectrum to rotating machinery diagnostics. Orbit First Quarter., 20(1), 17-21.

[32] Hajjara, S., Abdallah, M., \& Hudaib, A. (2009). Digital image watermarking using localized biorthogonal wavelets. European Journal of Scientific Research., 26(4), 594-608.

[33] Hariharan, G., \& Kannan, K. (2010). Haar wavelet method for solving FitzHugh-Nagumo equation. International Journal of Computational \& Mathematical Sciences., 4(6), 281-285.

[34] Hassan, S., Al-Saegh, M., Mohamed, A., \& Batarfi, H. (2011). Haar wavelet spectrum of a pulsed-driven qubit. Nonlinear Optics, Quantum Optics: Concepts in Modern Optics., 42(1), 37-50.

[35] Huang, M., Jiang, L., Liaw, P. K., Brooks, C. R., Seeley, R., \& Klarstrom, D. L. (1998). Using acoustic emission in fatigue and fracture materials research. JOM Nondestructive Evaluation: Overview., 50(11), 1-12. 
[36] Igarashi, T., \& Hamada, H. (1982). Studies on the vibration and sound of defective roller bearings (First report: vibration of ball bearing with one defect). Bulletin of the Japan Society of Mechanical Engineers., 25(204), 994-1001.

[37] Jardine, A., Lin, D., \& Banjevic, D. (2006). A review on machinery diagnostics and prognostics implementing condition-based maintenance. Mechanical Systems and Processing., 20(7), 1483-1510.

[38] Jia, M., \& Wang, Y. (2003). Application of wavelet transformation in signal processing for vibrating platform. Journal of Shenyang Institute of Technology., 22(3), 53-55.

[39] Johnstone, I. M., Kerkyacharian, G., Picard, D., \& Raimondo, M. (2004). Wavelet deconvolution in a periodic setting. Journal of the Royal Statistical Society: Series B (Statistical Methodology)., 66(3), 547-573.

[40] Kang, P., \& Birtwhistle, D. (2003). Condition assessment of power transformer onload tap-changers using wavelet analysis. IEEE Transactions on Power Delivery., 18(1), 78-84.

[41] Karimi, H., \& Robbersmyr, K. (2011). Signal analysis and performance evaluation of a crash test with a fixed safety barrier based on Haar waveletes. International Journal of Wavelets, Multiresolution \& Information Processing., 9(1), 131-149.

[42] Knezevic, J. (1993). Reliability, maintainability and supportability engineering: A probabilistic approach. McGraw Hill.

[43] Lahdelma, S., \& Juuso, E. (2007). Advanced signal processing and fault diagnosis in condition monitoring. Non-destructive Testing and Condition Monitoring., 49(12), 719-725.

[44] Lebedeva, E., \& Protasov, V. (2008). Meyer wavelets with least uncertainty constant. Mathematical Notes., 84(5), 680-687.

[45] Leducq, D. (1990). Hydraulic noise diagnostics using wavelet analysis. Proceedings of the International Conference on Noise Control Engineering., 997-1000.

[46] Lepik, Ü. (2011). Buckling of elastic beams by the Haar wavelet method. Estonian Journal of Engineering., 17(3), 271-284.

[47] Leske, S., \& Kitaljevich, D. (2006). Managing gearbox failure. Dewi Magazine., 29.

[48] Mc Fadden, P. D. (1987). Examination of a technique for the early detection of failure in gears by signal processing of the time domain average of the meshing vibration. Mechanical Systems and Signal Processing., 1(2), 173-183.

[49] Mc Fadden, P. D. (1996). Detecting fatigue cracks in gears by amplitude and phase demodulation of the meshing vibration. Journal of Vibration, Acoustics, Stress and Reliability in Design., 108, 165-170. 
[50] Mc Millan, D., \& Ault, G. W. (2008). Condition monitoring benefit for onshore wind turbines: Sensitivity to operational parameters. IET Renewable Power Generation., 2(1), 60-72.

[51] Misrikhanov, A. M. (2006). Wavelet transform methods: Application in electroenergetics. Automation and Remote Control., 67(5), 682-697.

[52] Moubray, J. (1997). Reliability-centered maintenance. New York: Industrial Press.

[53] Nakhaeinejad, M., \& Ganeriwala, S. Observations on dynamic responses of misalignments. Technologial Notes. SpectraQuest Inc., http://spectraquest.com/.

[54] Newland, D. E. (1999). Ridge and phase identification in the frequency analysis of transient signals by harmonic wavelets. Journal of Vibration and Acoustics, Transactions of the ASME., 121(2), 149-155.

[55] Novaes de, G., Alencar, E., \& Kraj, A. Remote conditioning monitoring system for a hybrid wind diesel system-application at Fernando de Naronha Island. http:// www.ontario-sea.org.

[56] Oberst, U. (2007). The Fast Fourier Transform. SIAM Journal on Control \& Optimization., 46(2), 1-45.

[57] Ocak, H., \& Loparo, K. A. (2001). A new bearing fault detection and diagnosis Scheme based on Hidden Markov modeling of vibration signals. Acoustics, Speech and Signal Processing., 5, 3141-4144.

[58] Patil, S., Kasturiwala, S., Dahad, S., \& Jadhav, C. (2011). Wavelet tool: Application for human face recognition. International Journal of Engineering Science E Technology., 3(3), 2392-2398.

[59] Pedregal, D. J., García, F. P., \& Roberts, C. (2009). An algorithmic approach for maintenance management. Annals of Operations Research., 166, 109-124.

[60] Peng, Z., \& Chu, F. (2004). Application of the wavelet transform in machine condition monitoring and fault diagnostics: a review with bibliography. Mechanical Systems and Signal Processing., 18, 199-221.

[61] Peters, S. T. (1998). Handbook of composites. Chapman \& Hall. London., 839-855.

[62] PROTEST (PROcedures for TESTing and measuring wind energy systems). (2009). Deliverable D1: State of the art report. FP7-ENERGY-2007-1-RTD.

[63] Quek, S. T., Wang, Q., Zhang, L., \& Ang, K. K. (2001). Sensitivity analysis of crack detection in beams by wavelet technique. International Journal of Mechanical Sciences., 43(12), 2899-2910.

[64] Rumsey, M. A., \& Musial, W. (2001). Application of infrared thermography nondestructive testing during wind turbine blade tests. Journal of Solar Energy Engineering., 123(4), 271. 
[65] Samsi, R., Ray, A., \& Mayer, J. (2009). Early detection of stator voltage imbalance in three-phase induction motors. Electric Power Systems Research., 79(1), 239-245.

[66] Schmitt, E., Idowu, P., \& Morales, A. (2010). Applications of wavelets in induction machine fault detection. Ingeniare. Revista chilena de ingeniería., 18(2), 158-164.

[67] Schoen, R. R., Lin, B. K., Habetler, T. G., Schlag, J. H., \& Farag, S. (1995). An unsupervised, on-line system for induction motor fault detection using stator current monitoring. IEEE Transactions on Industry Applications., 31(6), 1280-1286.

[68] Schroeder, K., Ecke, W., Apitz, J., Lembke, E., \& Lenschow, G. (2006). A fibre Bragg grating sensor system monitors operational load in a wind turbine rotor blade. Measurement Science and Technology., 17(5), 1167-1172.

[69] Sedighizadeh, M., \& Rezazadeh, A. (2008). Nonlinear model identification and PI control of wind turbine using neural network adaptive frame wavelets. International Journal of Applied Engineering Research., 3(7), 861-877.

[70] Sekhar, A. S., \& Prabhu, B. S. (1995). Effects of coupling misalignment on vibration of machines. Journal of Sound and Vibration., 185(4), 655-671.

[71] Smith, A. M. (1993). Reliability-centred maintenance. New York: McGraw-Hill, Inc.

[72] Smith, B. M. (1978). Condition monitoring by thermography. NDT International, 11(3), 121-122.

[73] Srinivas, H. K., Srinivasan, K. S., \& Umesh, K. N. (2010). Application of artificial neural network and wavelet transform for vibration analysis of combined faults of unbalances and shaft bow. Advances in Theoretical and Applied Mechanics., 3(4), 159-176.

[74] Staszewski, W. J., \& Tomlinson, G. R. (1994). Application of the wavelet transform to fault detection in a spur gear. Mechanical Systems and Signal Processing., 8(3), 289-307.

[75] Staszewski, W. J., Pierce, S. G., Worden, K., \& Culshaw, B. (1999). Cross-wavelet analysis for lamb wave damage detection in composite materials using optical fibres. Key Engineering Materials., 167, 373-380.

[76] Strang, G. (1992). The optimal coefficients in Daubechies wavelets. Physica D: Nonlinear Phenomena., 60, 239-244.

[77] Strang, G., \& Nguyen, T. (1997). Wavelets and filter banks. Wellesley-Cambridge Press.

[78] Subramanian, S., Badrilal, M., \& Henry, J. (2010). Wavelet transform based differential protection for power transformer and classification of faults using SVM and PNN. International Review of Electrical Engineering., 5(5), 2186-2198.

[79] Sugumaran, V., \& Ramachandran, K. I. (2009). Wavelet selection using Decision tree for fault diagnosis of roller bearings. International Journal of Applied Engineering Research., 4(2), 201-225. 
[80] Suh, J. H., Kumara, S. R. T., \& Mysore, S. P. (1999). Machinery fault diagnosis and prognosis: Application of advanced signal processing techniques. CIRP Annals- Manufacturing Technology., 48(1), 317-320.

[81] Sun, Q., \& Tang, Y. (2002). Singularity analysis using continuous wavelet transform for bearing fault diagnosis. Mechanical Systems and Signal Processing., 16(6), 1025-1041.

[82] Sung, C. K., Tai, H. M., \& Chen, C. W. (2000). Locating defects of a gear system by the technique of wavelet transform. Mechanism and Machine Theory., 35(8), 1169-1182.

[83] Swiercz, E. (2011). Automatic classification of LFM signals for radar emitter recognition using wavelet decomposition and LVQ classifier. Physical Aspects of Microwave and Radar Applications., 119(4), 488-494.

[84] Tan, C. C. (1990). Application of acoustic emission to the detection of bearing failures. Proceedings Tribology Conference. Brisbane., 110-114.

[85] Tse, P. W., Peng, Y. H., \& Yam, R. (2001). Wavelet analysis and envelope detection for Rolling element bearing fault diagnosis. Their effectiveness and flexibilities. ASME Journal of Vibration and Acoustics., 123, 303-310.

[86] Van Dijck, G., \& Van Hulle, M. M. (2011). Information theory filters for wavelet packet coefficient selection with application to corrosion type identification from acoustic emission signals. Sensors., 11(6), 5695-5715.

[87] Venkatesh, S., Ayyaswamy, S., \& Hariharan, G. (2010). Haar wavelet method for solving initial and boundary value problems of Bratu-type. International Journal of Computational \& Mathematical Sciences., 4(6), 286-289.

[88] Wang, D., Miao, Q., Fan, X., \& Huang, H. Z. (2009). Rolling element bearing fault detection using an improved combination of Hilbert and wavelet transform. Journal of Mechanical Science and Technology., 23, 3292-3301.

[89] Wang, Q., \& Deng, X. M. (1999). Damage detection with spatial wavelets. International Journal of Solids and Structures., 36(23), 3443-3468.

[90] Wang, W. Q., Ismail, F., \& Golnaragh, M. F. (2001). Assessment of gear damage monitoring techniques using vibration measurements. Mechanical Systems and Signal Processing., 15(5), 905-922.

[91] Wei, J., \& Mc Carty, J. (1993). Acoustic emission evaluation of composite wind turbine blades during fatigue testing. Wind Engineering., 17(6), 266-274.

[92] Wismer, N. J. (1994). Gearbox analysis using cepstrum analysis and comb liftering. Application Note. Brüel \& Kjaer. Denmark.

[93] World Wind Energy Association. World wind energy report 2009. http://www.wwindea.org.

[94] Wu, J., \& Liu, C. (2008). Investigation of engine fault diagnosis using discrete wavelet transform and neural network. Expert Systems with Applications., 35, 1200-1213. 
[95] Xu, M., \& Marangoni, R. (1994). Vibration analysis of a motor-flexible coupling-rotor system subjected to misalignment and unbalance Part I: Theoretical model and analysis. Journal of Sound and Vibration., 176(5), 663-679.

[96] Yacamini, R., Smith, K. S., \& Ran, L. (1998). Monitoring torsional vibrations of electro-mechanical systems using stator currents. Journal of Vibration and Acoustics, Transactions of the ASME., 120(1), 72-79.

[97] Yang, X., Shi, Y., \& Yang, B. (2011). General framework of the construction of biorthogonal wavelets based on Bernstein bases: theory analysis and application in image compression. 5(1), 50-67. 
